Jimmy Zurek

* 1971 Vienna, Austria | Vienna, Austria

Jimmy Zurek's work is primarily influenced by the 1980s, an era of increasing global capitalism, political upheaval, worldwide mass media, wealth discrepancies and unique music and fashion, characterised by hip hop and electronic pop music. This has had a strong impact on the generation of artists growing up during this decade. The fall of the Berlin Wall at the end of the 1980s signified the end of the Cold War, yet the era was also distinguished by the African Famine. During this time prominent art movements included Neo Geo, The Pictures Generation and Neo-Expressionism, which took a particular hold in Germany, France and Italy. Artists such as Anselm Kiefer, Jörg Immendorf, Enzo Cucchi, Francesco Clemente and Julian Schnabel were key artists working at this time, alongside Jean-Michel Basquiat, Keith Haring and Kenny Scharf, who developed the street art and graffiti movements, which quickly gained an influential reputation.

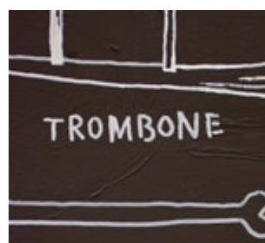

BEEF BONE

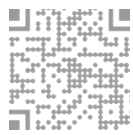

“...with my paintings i archive my past, my experiences that i have vmade with music and fine arts. over decades i have gathered my thoughts in lists to get my thoughts in order, lists of my personal music and art universe. after i have finished the process of collecting and ordering, i connect the lists with my political observations. i am showing the culture of american hip hop which recounts the history of afro-americans and other people of colour in the united states who have endured slavery. my work deals directly with systematically organised racism of the past and present, including modern day slavery. racism cannot be separated from capitalism. Music and texts (lyrics), paintings \& graphics, installation, theatre performances, photography and video. owner of the record label 'no risk no disk'." Inventor of the clit synth trousers. i am indebted to jean michel basquiat.
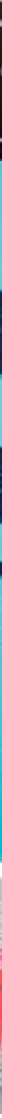

\title{
PIG BONE
}





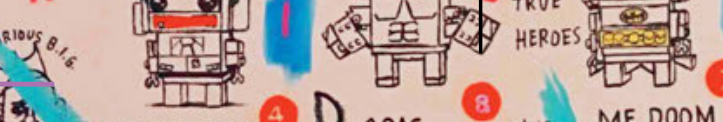

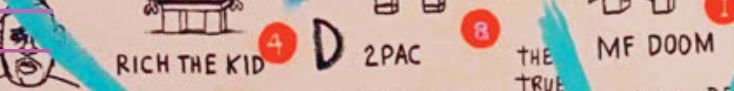
THE MF DOOM
TRUE
DE (2) Def
Jam ings n+DEFJAM + DEFJIM +++ RecORAS 11,12 WE DON' BELIEVE PLAYIN d) Y. YOU CAUSE WE WITH

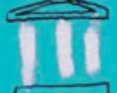

$M F A=$ MUSEUM OF

MOTHERFUCKIN ART

JROP

IT

TAKE
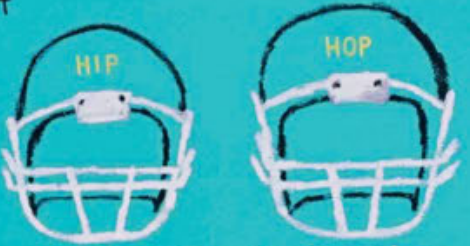
YOURSELF W

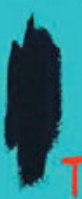

WE DON'T BELIEVE

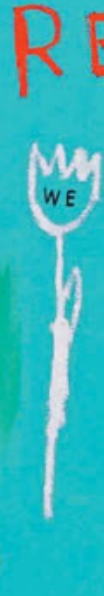

\section{ART WITH}

OVER

RESPONSIBILITY

HOT

ONLY

HANG

HOT

HOT

minovinus

Bosch

7 tas

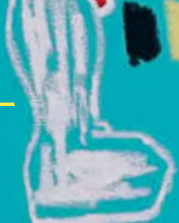

HARGEABLE-

)

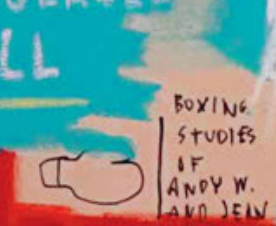
HERONMUUS WETHE (rou! b)

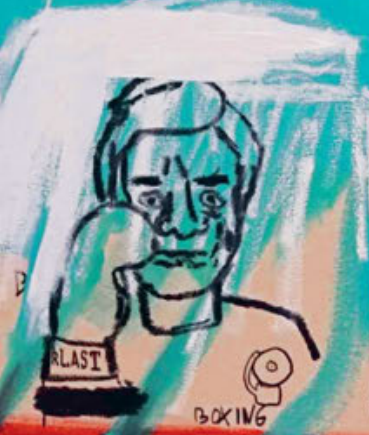

\section{$B Y$}

A TRIBE
PEOPLE

PEOPLE

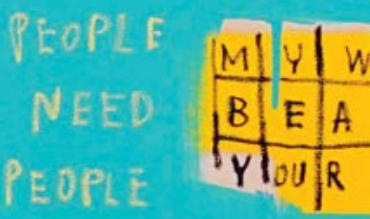

CALLED

QUEST
REVDLITION

NEED

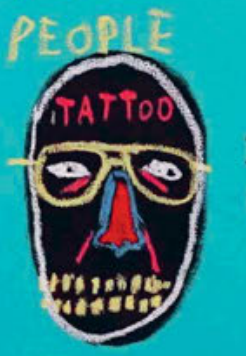

$29 I$

$A T R I B E$

CALLED

PK

VEW NEW

YokK York

STATE StaTE A : 0

MIND

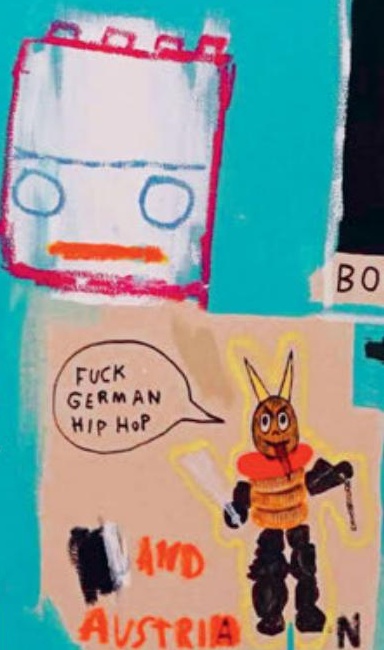


